\title{
CARACTERIZAÇÃO DO RESíDUO DE CORTE DE MÁRMORE E GRANITO DE MARMORARIA E ANÁLISE DA VIABILIDADE DE SUBSTITUIÇÃO PARCIAL DO CIMENTO PORTLAND PARA PRODUÇÃO DE PAVERS
}

\section{CHARACTERIZATION OF THE CUTTING CEMENT AND MARBLE GRANITE AND ANALYSIS OF THE VIABILITY OF PARTIAL CUT OF THE PORTLAND CEMENT FOR THE PRODUCTION OF PAVERS}

\author{
Andréa Cristina Félix da Cruz ${ }^{1}$ \\ Ricardo de Freitas Cabral ${ }^{2}$ \\ Cirlene Fourquet Bandeira ${ }^{3}$ \\ Sérgio Roberto Montoro ${ }^{4}$
}

Resumo: O acondicionamento final dos resíduos de corte de mármore e granito de marmoraria no Brasil, geralmente é feito de forma incorreta. Dessa forma, novas práticas educativas devem ser estudadas em busca de propostas que ofereçam possibilidades de mudanças, tanto pela sociedade quanto pelas empresas geradoras de tais resíduos. Nesse entendimento, vale destacar que resíduos sólidos como estes tendem a crescer em grandes proporções, o que torna necessário minimizar os prejuízos que causam. 0 objetivo do presente estudo foi avaliar a possibilidade de reciclar e reutilizar resíduos de mármore e granito substituindo parcialmente o cimento Portland na produção de pavers - pisos intertravados, trazendo benefícios para o meio ambiente, além de produzir peças que garantam a permeabilidade do solo, em conformidade com as normas vigentes. Para tanto, foi utilizado como matérias-primas, o RCMG de marmoraria, cimento, areia e água para desenvolver esse estudo, e normas brasileiras - NBRs como fonte de orientação. Foram confeccionados corpos de prova para ensaios de resistência à compressão, absorção de água e microscopia eletrônica de varredura. Os ensaios foram realizados nos Laboratórios do UniFOA. Investigou-se a viabilidade técnica para fabricação de pavers com substituição parcial de $10 \%$ e $20 \%$ do cimento Portland por resíduos de mármore e granito. Os resultados obtidos demonstraram que foi viável a aplicação, pois apresentaram aumento da resistência mecânica com a substituição do cimento por RCMG - resíduo do corte de mármore e granito - na proporção de $10 \%$.

Palavras-chave: Piso de concreto; marmoraria; reciclagem; sustentabilidade.

\begin{abstract}
The final packaging of marble and granite marble cutting waste in Brazil is usually performed incorrectly. Thus, new educational practices should be studied in the search for proposals that offer possibilities for change, both by the society and by the companies that generate such residues. In this understanding, it is noteworthy that solid waste such as these tend to grow in large proportions, which makes it necessary to minimize the damage they cause. The aim of the present study was to evaluate the possibility of recycling and reusing marble and granite residues partially replacing Portland cement in the production of interlocking pavers, bringing benefits to the environment, as well as producing pieces that guarantee soil permeability, in accordance with current regulations. To this end, the RCMG of marble, cement, sand and water were used as raw materials to develop this study, and Brazilian standards - NBRs were adopted as a source of guidance. Specimens were made for tests of compressive strength, water absorption and scanning electron microscopy. The tests were performed at UniFOA Laboratories. The technical feasibility of pavers with partial replacement of $10 \%$ and $20 \%$ of Portland cement by marble and granite residues was investigated. The results showed that the application was feasible, since they showed increased mechanical resistance with the replacement of cement by RCMG - marble and granite cutting residue - in the proportion of $10 \%$
\end{abstract}

\footnotetext{
${ }^{1}$ Graduada, Discente do Mestrado em Materiais - UniFOA, Brasil. E-mail: andreafelix.engcivil@gmail.com.

${ }^{2}$ Doutor, Docente do Centro Universitário Geraldo Di Biase, Brasil. E-mail: ricfisic@gmail.com.

3 Doutora, Docente do Mestrado em Materiais - UniFOA, Brasil. E-mail: cirlene.bandeira@foa.org.br.

${ }^{4}$ Doutor, Docente do Mestrado em Materiais - UniFOA, Brasil. E-mail: sergio.montoro@foa.org.br.
} 
Keywords: Concrete floor; marble factory; recycling; sustainability.

\section{INTRODUÇÃO}

A poluição ambiental pode ocorrer de diversas formas, uma delas são os resíduos industriais que além de causar problemas ao meio ambiente, apresentam graves danos socioeconômicos. Pode-se afirmar que a reutilização dos rejeitos sólidos gerados na Indústria da Construção Civil, contribui para a redução dos custos e danos ambientais, quando tratados ou dado a destinação correta (LUCAS; BENATTI, 2008).

O setor da construção civil utiliza de forma abundante, diversos recursos naturais, dentre estes, as rochas ornamentais, que são largamente usadas como pisos, acabamentos, revestimentos, mobiliários, dentre outros. Sendo assim, promove grande impacto ambiental, em virtude da alta produção de resíduos, os chamados resíduos de construção civil - RCC (CHIODI FILHO; RODRIGUES, 2009).

Nas oficinas de beneficiamento (marmorarias), mármores e granitos, ainda em sua forma bruta, são recortados e polidos. Neste processo, resíduos líquidos e sólidos são gerados (CHIODI FILHO; RODRIGUES, 2009).

Consequentemente, reciclar e reutilizar são alternativas relevantes na busca do desenvolvimento sustentável, tendo em vista a economia de matérias-primas não renováveis e de energia, assim reduz-se os impactos ambientais (MENEZES; NEVES; SOUZA; MELO; FERREIRA, 2009).

Independente da fonte geradora, a produção de resíduos ainda é um grande desafio a ser solucionado pela sociedade contemporânea, como exemplo, a destinação final do lixo, especificamente neste estudo, os resíduos sólidos de mármore e granito (RODRIGUES; FERREIRA, 2010).

A empregabilidade destas rochas é benéfica, porém, os rejeitos gerados prejudicam ao meio ambiente, por serem derivados industriais de mármore e granito.

Os problemas mais relevantes neste setor são a ausência de gestão sustentável dos recursos; a quantidade de resíduos gerados; entre outros. A vista disso, a utilização em grande escala de rochas ornamentais traz impactos ambientais como a poluição aérea e promove o assoreamento dos rios (ALIABDO; ELMOATY; AUDA, 2014).

Nesse seguimento, as empresas poluidoras, têm sido levadas a conscientização para um desenvolvimento sustentável, ou seja, progredir sem prejudicar futuras gerações. O essencial no momento é encontrar meios para obter o progresso respeitando o meio ambiente.

Nesse sentido, acredita-se que a reciclagem de resíduos de granito na fabricação de pavers seja relevante, devido ao fato de contribuir para preservação ambiental, tendo em vista a possibilidade de reduzir o consumo de cimento Portland, uma vez que sua produção gera poluentes, além de evitar que estes rejeitos sejam inadequadamente 
armazenados, observando-se os princípios de sustentabilidade e responsabilidade social. Para tanto, é recomendado reciclar o material ora em estudo, antes de descartálo totalmente no meio ambiente.

Em vista disso, pretende-se avaliar de forma experimental a incorporação dos resíduos de mármore e granito na fabricação de pavers, pisos intertravados, utilizandose das metodologias conforme os procedimentos das Normas da ABNT e da Ciência dos Materiais.

O presente estudo é relevante devido ao fato de se demonstrar meios alternativos que possibilitem reciclar e reutilizar os resíduos de mármore e granito, oriundos das oficinas de beneficiamento. Para tanto pretende-se demonstrar a viabilidade da substituição nas proporções de $10 \%$ e $20 \%$ do cimento Portland por rejeito pastoso de mármore e granito, também conhecido como lodo ou lama de marmoraria, para fabricação de pavers.

Com isto, o meio ambiente será beneficiado, além de produzir peças que garantam a permeabilidade do solo, de acordo com as normas referentes à sustentabilidade.

O presente trabalho teve como objetivo geral, analisar a viabilidade de se utilizar parcialmente os resíduos de mármores e granito no concreto para produção de pavers.

\section{MATERIAIS E MÉTODOS}

\subsection{Rochas ornamentais}

São consideradas rochas ornamentais, aquelas que após serem beneficiadas, destacam características exclusivas, em virtude da estrutura, textura e disposição dos minerais (ABREU; RUIZ; CARUSO,1990).

Brandão, Sardou Filho e Queiroz (1991), afirmam que essa nomenclatura contribui para especificar as rochas que apresentam características de "pedras ornamentais", que são aquelas que podem ser utilizadas como adornos in natura, de diversas formas.

As rochas ornamentais recebem uma classificação petrológica precisa. No entanto, nas transações comerciais, subdividem-se em dois grupos, mármores e granitos. Os aspectos estéticos mais importantes são a cor, textura, tamanho do grão, como também as características tecnológicas como durabilidade (GIACONI, 1998).

O granito é considerado rocha ígnea, excessivamente rígida, composta de muitos minerais, atribuindo-lhe geralmente coloração rosada para grafite ou preto. $O$ termo granito (granite) é um agrupamento enorme no setor de rochas ornamentais (LLOPE, 2011).

A composição mineralógica desses granitos está associada a diferentes aglutinações. O quartzo, feldspato, mica e os anfibólios são os minerais que dominam 
as rochas graníticas e granitoides. As rochas graníticas são consideradas no setor industrial, como: granito propriamente dito, dioritos, granodioritos, sientitoa, dentre outras, e apresentam dureza 7 na escala de mohs (ABREU; RUIZ; CARUSO, 1990).

Quanto ao termo, mármore, abrange as rochas metamórficas, predominando em sua composição o calcite. Qualquer calcário ao receber um polimento superficial, pode ser considerado mármore, pois apresenta uma pluralidade de cores que provém de sedimentos e outros minerais (CEVIK et al., 2010).

Mármore e granito têm sido muito utilizados na construção civil devido sua maior resistência e durabilidade, tendo em vista os padrões estéticos e possibilidades de criatividade em pisos e fachadas.

\subsection{Concreto}

O concreto é material construtivo, encontrado nas casas de alvenaria, nos edifícios, em rodovias, pontes, pisos intertravados, dentre outras. Presume-se que se consome por ano em torno de onze bilhões de toneladas de concreto. A Federación Iberoamericana de Hormigón Premesclado (FIHP). afirma que o consumo médio anual é aproximadamente de 1,9 tonelada de concreto por habitante (IBRACON, 2009).

De acordo com a ASTM (American Society for Testing and Materials), concreto é definido como um material compósito constituído de aglomerante (cimento e água) aglutinando partículas de naturezas diferentes. A areia, pedregulho, seixos, rocha britada, e demais tipos de resíduos são agregados que compõem o concreto. Além disso, no estado fresco, o concreto pode ter suas propriedades alteradas quando se adiciona substâncias químicas como os aditivos (IBRACON, 2009).

\subsubsection{Cimento}

É um produto que apresenta características adesivas e coesivas, tornando possível ligar partículas de minerais entre si, formando um todo consistente. A utilização de materiais que possuem propriedades cimentícias com finalidade de construir é uma prática muito ancestral na história da civilização (NEVILLE, 1982).

Em 1756, o inglês John Smeaton passou a desenvolver o cimento com mais qualidade. Ele conseguiu obter um produto com elevada resistência através de calcinação de calcários moles e argilosos. Em 1818, o inventor do cimento artificial, o francês Vicat alcançou resultados parecidos aos de Smeaton misturando componentes argilosos e calcários (KIHARA; CENTURIONE, 2005). Em 1824, Joseph Aspdin, construtor inglês, fez um experimento queimando pedras calcárias e argila simultaneamente, obtendo um pó fino. Essa mistura ao secar, ficava dura como as pedras utilizadas nas construções, visto que ao ser misturado com a água não dissolvia. 
Esse produto foi nomeado de cimento Portland, por ser durável, sólido como as rochas da ilha britânica de Portland (KIHARA; CENTURIONE, 2005).

O cimento Portland é um composto de: Silicato tricálcico (C3S), Silicato dicálcico (C2S), Aluminato tricálcico (C3A). e Ferro aluminato tetracálcico (C4AF). Os responsáveis pelas primeiras reações são os aluminatos, atingindo valores inferiores de resistência aos esforços mecânicos. Os silicatos são fundamentais em relação à resistência, sendo o C3S nas primeiras idades e o C2S em idades maiores (PETRUCCI, 2007).

\subsection{2 Água}

A água é um componente tão importante quanto o cimento para o concreto. Tem a finalidade de gerar reações de hidratação dos compostos do cimento, levando ao seu endurecimento, e aumentar a trabalhabilidade.

As substâncias anidras presentes no cimento Portland, ao entrar em contato com a água, formam produtos hidratados. O cimento ao ser hidratado transforma os compostos anidros mais solúveis em compostos hidratados menos solúveis. Esse processo de hidratação envolve a estabilização dos minerais do clínquer por meio da água, em temperatura ambiente, o que gera compostos mineralogicamente, como o CS-H, etringita e portlandita (PETRUCCI, 2007).

Esta hidratação do cimento Portland depende da relação água-cimento, finura, temperatura, procedimentos de cura e outros fatores físicos e não somente dos componentes mineralógicos do clínquer e das adições ativas do cimento. Desse modo, os elementos químicos, junto com a água, rearranjam-se em novos sistemas cristalinos, dando rigidez à mistura (KIHARA; CENTURIONE, 2005).

\subsubsection{Agregados}

Os agregados são materiais granulares que não possuem forma, volume definidos, e são inertes, ideais para serem usados em obras de engenharia. Geralmente estão presentes na elaboração de bases para calçamentos, confecção de argamassas e concretos, dentre outras (PETRUCCI, 2007).

As propriedades dos agregados influenciam na durabilidade e no desempenho estrutural do concreto, por serem ligados num todo monolítico através da pasta de cimento. Devido a suas características técnicas, o concreto passa a ter mais estabilidade dimensional e resistência em relação à pasta de cimento pura (NEVILLE, 1982).

Os agregados podem ser graúdos e miúdos, de acordo com sua origem. Mehta e Monteiro (1994), afirmam que fragmentos maiores do que 4,8 milímetros são agregados 
graúdos e os menores do que 4,8 milímetros são agregados miúdos. Recebem ainda uma classificação como naturais que são: areia, cascalho, pedras e artificiais, rejeitos originários das siderúrgicas, dentre outros. Quanto à categoria dos agregados artificiais, inclui ainda os materiais processados termicamente, como argila, que ao ser difundido, são usados produção de concreto leve.

\subsubsection{Agregados aditivos}

São elementos adicionados ao concreto com o objetivo de reforçar algumas características, até mesmo facilitar seu preparo e utilização. De acordo com a NBR 12.655:2015 (ASSOCIAÇÃO BRASILEIRA DE NORMAS TÉCNICAS, 2015), aditivos são materiais que se adicionam ao concreto no decorrer do processo de mistura, sendo que a quantidade não pode ser acima de $5 \%$ sobre a massa do cimento contido no concreto, para que se altere as propriedades da mistura no estado fresco e/ou no estado endurecido (PETRUCCI, 2007).

A aplicação de aditivos no concreto tem a finalidade de aprimorar a trabalhabilidade, agilizar a pega, acelerar o endurecimento nas idades exordiais, dentre outras. Segundo Andrade e Helene (2007), os aditivos superplastificantes contribuem para que o concreto seja mais resistente e mais durável. Seu uso provoca alteração na reologia da pasta que fica mais fluida.

\subsubsection{Agregados minerais}

As adições têm como objetivo somar ou substituir de forma parcial o cimento. Já os aditivos, esses têm a função de alterar as características do cimento, sem modificar sua proporção na composição do concreto. Conforme sua ação físico-química no concreto, as adições minerais são classificadas nos grupos de materiais pozolânicos, materiais cimentantes e filler (MEHTA; MONTEIRO,1994).

\subsection{Pisos intertravados de concreto}

Os pavimentos são classificados como pavimentos flexíveis ou rígidos. Os pavimentos flexíveis são aqueles que recebem revestimentos asfáltico (CAUQ). Já os pavimentos rígidos são aqueles revestidos de placas de concreto de cimento Portland (PCS).

Os pisos intertravados de concreto encontram-se no grupo dos pavimentos rígidos e são utilizados principalmente no revestimento de acostamentos, recuos, pátios e vias de baixo tráfego ou baixa velocidade (DNIT, 2004).

Conhecidos como pavers ou paviess, os blocos intertravados de concreto, são 
pré-fabricados, maciços e que viabiliza pavimentar de forma plena uma superfície. $\mathrm{O}$ intertravamento capacita o material resistir aos movimentos de deslocamento individual, horizontal, vertical, de rotação ou giração em relação às peças adjacentes, conforme Figura 1 (FIORITI, 2007).

Figura 1 - Corte esquemático: assentamento intertravado



Fonte: RHINOPISOS, 2019.

Os blocos intertravados se destacam devido as vantagens que oferecem, como o fácil assentamento, rápida liberação da pavimentação para o tráfego, acessibilidade às redes subterrâneas, praticidade na manutenção e durabilidade. Além disso, esse produto se destaca devido a sua eficácia ambiental, permeabilizando o solo e possibilitando que rejeitos sejam utilizados em sua composição. Atualmente é possível encontrar uma grande diversidade de modelos, tamanhos e cores de blocos, Figura 2 (FIORITI, 2007).

Figura 2 - Tipos de pisos intertravados de concreto

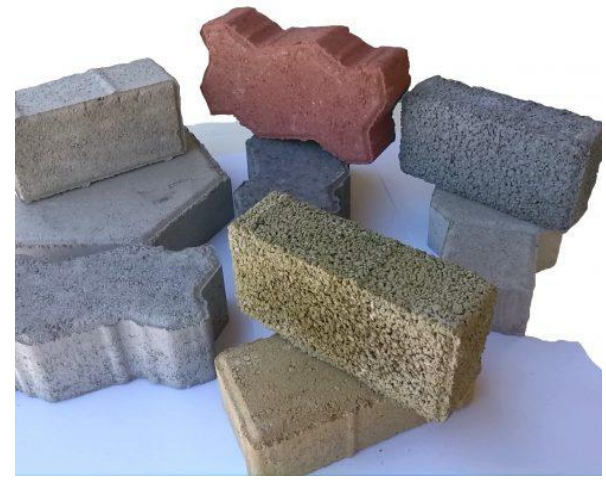

Fonte: NEOBLOCOSP, 2019.

\subsection{Uso de RCMG na confecção de pavers}

A maioria dos processos que tem como meta a atividade econômica, gera resíduos, na forma de gases, líquidos ou sólidos, que degradam o meio ambiente, dificultando um desenvolvimento sustentável (GONÇALVES, 2000). 
No Brasil, estima-se que a atividade de corte de mármore e granito gera em torno de 240.000 toneladas/ano de resíduos, distribuídas entre Espírito Santo, Bahia, Ceará, Paraíba, entre outros Estados (GONÇALVES, 2000).

Sendo assim, essa grande quantidade de resíduos produzido no beneficiamento de mármores e granitos causam muitos problemas ambientais. Vale destacar que o Brasil é um dos maiores produtores de rochas ornamentais do mundo, sua produção chega a 7,8 milhões do total de 105 milhões de toneladas produzidos mundialmente, sendo que 1,25 milhões de toneladas são de resíduos relacionados à produção e ao beneficiamento das rochas (MATTA; APOLINÁRIO; SANTOS; RIBEIRO, 2013).

\section{MATERIAIS E MÉTODOS}

\subsection{Materiais}

As matérias-primas utilizadas neste trabalho na preparação do concreto foram adquiridas em loja de material de construção do comércio local. O RCMG foi doado por uma marmoraria localizada na cidade de Volta Redonda.

\subsubsection{Cimento}

O cimento Portland do tipo CP-V ARI, fabricante LIZ, foi utilizado por apresentar alta resistência nos primeiros dias de sua aplicação; ser um produto compatível com processos que necessitam do uso de superfluidificantes e atender às especificações da NBR 5733:1991.

\subsubsection{Resíduo do corte de mármore e granito (RCMG)}

O resíduo foi proveniente de dois locais: Marmoraria São Luiz e Marmoraria Gramil, ambas localizadas no município de Volta Redonda - RJ. O material foi coletado diretamente no tanque de sedimentação de cada empresa e armazenado em baldes plásticos. Em seguida, transportado para local aberto e arejado para secagem ao ar livre.

\subsubsection{Areia}

\section{(ASSOCIAÇÃO BRASILEIRA DE NORMAS TÉCNICAS, 2009)}

Foi utilizada areia de origem natural, oriunda de leito de rio, classificada pela norma NBR 7211:2009 (ASSOCIAÇÃO BRASILEIRA DE NORMAS TÉCNICAS, 2009) com granulometria média, entre $0,2 \mathrm{~mm}$ e $0,6 \mathrm{~mm}$ de diâmetro.

\subsubsection{Brita}

Utilizou-se a pedra britada classificada pela NBR 7211:2009 como brita 0, por ser um material indicado para uso na fabricação de pavers. 


\subsection{5 Água}

A água utilizada no preparo do concreto foi fornecida pelo Serviço Autônomo de Água e Esgoto - SAAE, do município de Volta Redonda.

\subsubsection{Aditivo}

Utilizou-se o aditivo "hagenblocoR1" do fabricante HAGEN DO BRASIL, desenvolvido para ser aplicado a concretos para fabricação de blocos e pavers.

\subsection{Métodos}

\subsubsection{Coleta e beneficiamento do Resíduo}

O resíduo do corte de marmoraria foi coletado e a amostra foi submetida à secagem ao ar livre, por $6 \mathrm{~h}$. O material seco foi coado, utilizando-se uma peneira de 150 mesh $(106 \mu \mathrm{m})$ e armazenado em recipiente apropriado.

\subsubsection{Caracterização das matérias primas}

Para fazer a caracterização das matérias primas foram utilizados os processos de análise granulométrica de todos os materiais secos. Além destes, o RCMG, também foi submetido à caracterização por difração de raio $X$.

\subsubsection{Análise da composição granulométrica}

Para fazer a análise granulométrica das matérias primas, utilizou-se o agitador de peneiras eletromecânico de bancada, fabricante Solotest, com capacidade para até 8 peneiras $\varnothing 8 X 2$ ", alimentação 110/220 V - 50/60 Hz. Foi utilizado o conjunto de peneiras sucessivas conforme NBR NM248 (ASSOCIAÇÃO BRASILEIRA DE NORMAS TÉCNICAS, 2003) de 2003. Através deste ensaio foram obtidos os valores do módulo de finura e o diâmetro máximo característico dos materiais. O ensaio foi realizado no Laboratório de Engenharia Civil do UniFOA.

\subsubsection{Microscopia Eletrônica de Varredura - MEV do RCMG}

Para a visualização de possíveis alterações na microestrutura, as amostras foram submetidas a microscopia eletrônica de varredura.

O ensaio foi realizado no Laboratório de Caracterização de Materiais do UniFOA no MEV da marca Hitachi, do modelo TM3000. As imagens foram ampliadas em 25X, 100X, 500X e 2000X, por um detector de elétrons secundários. Para esta análise, utilizou-se uma pequena fração do RCMG. 


\subsubsection{Corpos de Prova}

\subsubsection{Determinação do traço para confecção dos corpos de prova}

Utilizou-se as proporções 1: 2,4: 2,58: 0,6, cimento; areia; brita e água respectivamente, em massa, para confecção dos corpos de prova, de modo que a resistência característica à compressão de $35 \mathrm{MPa}$ fosse atingida. Foram preparadas dosagens com diferentes percentuais de adição do resíduo de mármore e granito, conforme apresentado na Tabela 1.

Tabela 1 - Proporções teóricas pretendidas por traço com as adições.

\begin{tabular}{ccccccc}
\hline \multicolumn{7}{c}{ DOSAGEM DOS MATERIAIS } \\
\hline $\begin{array}{c}\text { ADIÇÃO } \\
(\%) .\end{array}$ & $\begin{array}{c}\text { CIMENTO } \\
(\mathrm{KG}) .\end{array}$ & $\begin{array}{c}\text { RCMG } \\
(\mathrm{KG}) .\end{array}$ & $\begin{array}{c}\text { AREIA } \\
(\mathrm{KG}) .\end{array}$ & $\begin{array}{c}\text { BRITA } \\
(\mathrm{KG}) .\end{array}$ & $\begin{array}{c}\text { ÁGUA } \\
(\mathrm{L}) .\end{array}$ & $\begin{array}{c}\text { ADITIVO } \\
(\mathrm{ML}) .\end{array}$ \\
\hline Referência & 10.360 & 0 & 24.860 & 26.800 & 6,2 & 10 \\
10 & 9.324 & 1.036 & 24.860 & 26.800 & 6.6 & 10 \\
20 & 8.288 & 2.072 & 24.860 & 26.800 & 6.6 & 10 \\
\hline
\end{tabular}

Fonte: Os autores.

\subsubsection{Preparação dos moldes}

Foram preparados corpos de prova cilíndricos para análise da resistência à compressão axial, Tabela 2, de acordo com NBR 5738: 2016 (ASSOCIAÇÃO BRASILEIRA DE NORMAS TÉCNICAS, 2016).

Tabela 2 - Preparação dos corpos de prova.

\begin{tabular}{ccccc}
\hline Ensaio & \multicolumn{4}{c}{ Corpos de Prova } \\
& \multicolumn{4}{c}{ Quantidades por composição } \\
\hline Resistência à & Cilíndricos & Referência & $10 \%$ & $20 \%$ \\
compressão & $(10 \times 20 \mathrm{~cm})$ & 12 & 12 & 12 \\
\hline
\end{tabular}

Fonte: Os autores.

Os moldes receberam uma fina camada de óleo mineral para facilitar a liberação dos corpos de provas.

\subsubsection{Confecção dos corpos de prova}

Para a confecção dos corpos de prova, os agregados foram separados nas devidas proporções. Misturou-se primeiramente na betoneira, areia, brita, e nas composições com substituição parcial do cimento, o RCMG, com $70 \%$ da água. Feito isto, adicionou-se o cimento e o aditivo diluído no restante da água. Após homogeneização da mistura por cinco minutos, com a betoneira parada, realizou-se o Slump Test, termo inglês utilizado para controle do fator "a/c". 


\subsubsection{Ensaios com os corpos de prova}

\subsubsection{Absorção de Água e Índices de Vazios dos CP's cilíndricos}

O ensaio de índice de vazios e absorção de água foi realizado em conformidade com a NBR 9778:2009 (ASSOCIAÇÃO BRASILEIRA DE NORMAS TÉCNICAS, 2009). Foram separados 2 corpos de prova das composições sem adição de RCMG e 2 com as respectivas adições, com idade de 28 dias. Determinou-se a massa de cada amostra, em balança com capacidade para $30 \mathrm{~kg}$ do fabricante Welmy, modelo BCW 30 LCD.

\subsubsection{Resistência à compressão axial}

Quando as amostram atingiram as idades de 7, 14, 21 e 28 dias respectivamente, foram retiradas 03 unidades de cada composição do tanque de cura, para realização do ensaio mecânico à compressão axial, conforme a norma ABNT NBR 5738:2016 (ASSOCIAÇÃO BRASILEIRA DE NORMAS TÉCNICAS, 2016). Os ensaios de resistência mecânica à compressão axial, foram realizados no Laboratório de Engenharia Civil do UniFOA, em prensa EMIC, modelo DL10000, com capacidade máxima de $100 \mathrm{kN}$.

\subsubsection{Microscopia Eletrônica de Varredura do concreto}

Para a visualização de possíveis alterações na microestrutura, as amostras foram submetidas ao MEV. O ensaio foi realizado no Laboratório de Caracterização de Materiais do UniFOA no MEV da marca Hitachi, do modelo TM3000.

\section{RESULTADOS E DISCUSSÃO}

\subsection{Caracterização dos materiais como recebidos}

\subsubsection{Análise granulométrica dos agregados}

$\mathrm{Na}$ análise da distribuição granulométrica foi observado que o diâmetro máximo característico do RCMG apresentou dimensões $62,16 \%$ maiores, quando comparado ao cimento, porém, não excedendo a $75 \mu \mathrm{m}$, como também módulo de finura, cerca de $62 \%$ maior.

Foi verificado que $53 \%$ do total da amostra de areia permaneceram retidas na peneira $600 \square \mathrm{m}$, Tabela 3. De acordo com a NBR 7211:2009 (ASSOCIAÇÃO BRASILEIRA DE NORMAS TÉCNICAS, 2009), essa graduação correspondeu à areia média. Da mesma forma, ao realizar o ensaio com a brita "zero", verificou-se que a sua granulometria está em conformidade com a norma acima citada. 
Tabela 3 - Distribuição granulométrica dos Materiais.

\begin{tabular}{|c|c|c|c|c|c|c|c|}
\hline \multicolumn{2}{|c|}{ CIMENTO } & \multicolumn{2}{|c|}{ RCMG } & \multicolumn{2}{|c|}{ AREIA } & \multicolumn{2}{|c|}{ BRITA 0} \\
\hline Ret. & Acum. & Ret. & Acum. & Ret. & Acum. & Ret. & Acum. \\
\hline - & - & - & - & - & - & - & - \\
\hline - & - & - & - & - & - & - & - \\
\hline - & - & - & - & - & - & 43,1 & 43,1 \\
\hline - & - & - & - & - & - & 38,0 & 81,0 \\
\hline - & - & - & - & 2,2 & 2,2 & 18,0 & 99,0 \\
\hline - & - & - & - & 12,0 & 14,2 & 1,0 & 100,00 \\
\hline- & - & - & - & 53,0 & 67,2 & - & - \\
\hline- & - & - & - & 23,6 & 90,9 & - & - \\
\hline- & - & - & - & 7,6 & 98,5 & - & - \\
\hline 38,9 & 38,9 & 51,3 & 51,3 & - & - & - & - \\
\hline 61,1 & 100,0 & 48,7 & 100,0 & 1,5 & 100,0 & - & - \\
\hline \multicolumn{2}{|c|}{$<75 \mu \mathrm{m}$} & \multicolumn{2}{|c|}{$75 \mu \mathrm{m}$} & \multicolumn{2}{|c|}{$2,4 \mathrm{~mm}$} & \multicolumn{2}{|c|}{$4,8 \mathrm{~mm}$} \\
\hline \multicolumn{2}{|c|}{0,4} & \multicolumn{2}{|c|}{0,5} & \multicolumn{2}{|c|}{2,7} & \multicolumn{2}{|c|}{3,2} \\
\hline
\end{tabular}

Fonte: Os autores.

\subsubsection{Microscopia Eletrônica de Varredura - MEV do RCMG}

Nas imagens da Figura 3-a e 3-b, resultantes do MEV, observou-se que os grãos minerais do resíduo não possuem uma forma definida, apresentando partículas com geometria irregular, provavelmente em decorrência da quebra dos grãos no processo de corte e polimento das peças de mármore e granito.

Figura 3 - Microscopia Eletrônica de Varredura do resíduo (a). Ampliação em 1000x; (b). Ampliação em 2000x.

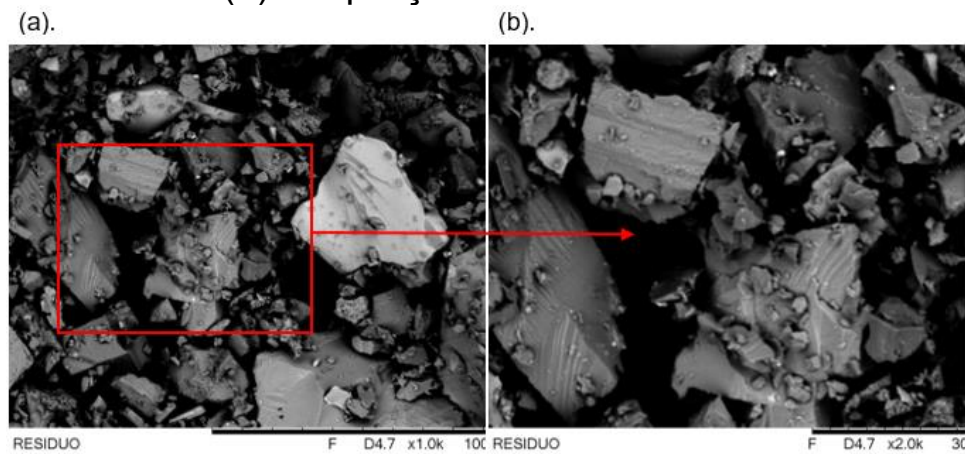

Fonte: Os autores.

Alves (2008), em estudos realizados, por meio do MEV, observou também que o resíduo apresentou grãos de variados tamanhos, e bem distribuídos ao longo da amostra. Quase metade da amostra apresentou partículas com dimensões inferiores a $40 \mu \mathrm{m}$. Essa observação está compatível com o resultado obtido no ensaio de granulometria, onde $51 \%$ dos grãos foram retidos na peneira $75 \mu \mathrm{m}$. 


\subsection{Caracterizações dos corpos de prova}

\subsubsection{Resistência à Compressão axial}

As propriedades mecânicas dos compósitos foram avaliadas por meio de ensaios mecânicos de resistência à compressão axial. Três corpos de prova de cada composição foram submetidos à análise. As amostras em que o cimento foi substituído na proporção de 10\%, apresentaram resistência mecânica superior, quando comparadas àquelas sem adição. Em contrapartida, aquelas em que a substituição do cimento correspondeu a $20 \%$ de RCMG, apresentaram resultados ligeiramente inferiores, Tabela 4.

Tabela 4 - Resultado do ensaio de resistência à compressão axial.

$\begin{array}{ccc}\begin{array}{c}\text { Referência } \\ \text { (MPa). }\end{array} & \begin{array}{c}10 \% \\ (\mathrm{MPa}) .\end{array} & \begin{array}{c}20 \% \\ (\mathrm{MPa}) .\end{array} \\ 33,47 \pm 2,23 & 35,14 \pm 0,39 & 31,32 \pm 2,21\end{array}$

Fonte: Os autores.

Quando paradas, a composição referência com as demais, verificou-se que aquelas com substituição de $10 \%$ apresentaram um aumento na resistência mecânica de aproximadamente $1,05 \%$, enquanto que a amostra com $20 \%$ teve uma queda de $0,94 \%$. Quanto maior a quantidade do pó residual de marmoraria, menor foi a resistência mecânica à compressão axial do compósito.

\subsubsection{Absorção de água por imersão e Índices de vazios}

Após 72 h de imersão, verificou-se a massa dos corpos de prova e em seguida, foi efetuada a pesagem de cada composição imersa em água. Ao substituir os valores nas equações 2 e 3 , foi observado que as composições apresentaram baixos índices de absorção de água com poucas variações, Tabela 5 . 
Tabela 5 - Absorção de água e Índice de vazios.

$$
\begin{array}{lll}
3,42 \% \pm 0,02 \% & 2,47 \% \pm 0,09 \% & 2,95 \% \pm 0,03 \% \\
7,31 \% \pm 0,29 \% & 5,05 \% \pm 0,51 \% & 6,28 \% \pm 0,03 \%
\end{array}
$$

Fonte: Os autores.

As composições com $10 \%$ de substituição de resíduos apresentaram menor percentual de absorção de água e índices de vazios, quando comparado com os CP's referência e as amostras com substituição de $20 \%$ do cimento.

Para Helene (2004), concretos com teor de absorção de água menor ou igual a $4,2 \%$ podem ser classificados como "Durável - Alto Desempenho".

\subsubsection{Micoscopia Eletrônica de Varredura do concreto}

As Figuras 4, 5 e 6, apresentaram imagens obtidas no MEV das amostras dos CP's rompidos aos 28 dias de cura. A amostra "referência" apresentou aspecto poroso e fissuras, Figura 4.

Figura 4 - Imagens do concreto aos 28 dias de cura - Referência (0\% de resíduo).



Fonte: Os autores.

Com a substituição do cimento na fração de 10\%, percebeu-se um concreto mais coeso, resultando no aumento da resistência mecânica como evidenciado nos testes de compressão axial, Figura 5. 
Figura 5 - Imagens do concreto aos 28 dias - 10\% de resíduo.

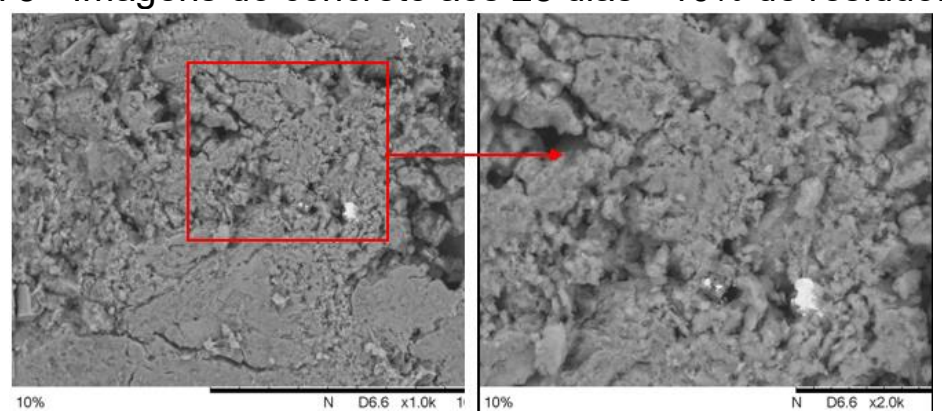

Fonte: Os autores.

A substituição em $20 \%$ do cimento não alterou o aspecto poroso e coeso do concreto, Figura 6.

Figura 6 - Imagens do concreto aos 28 dias de cura - 20\% de resíduo.

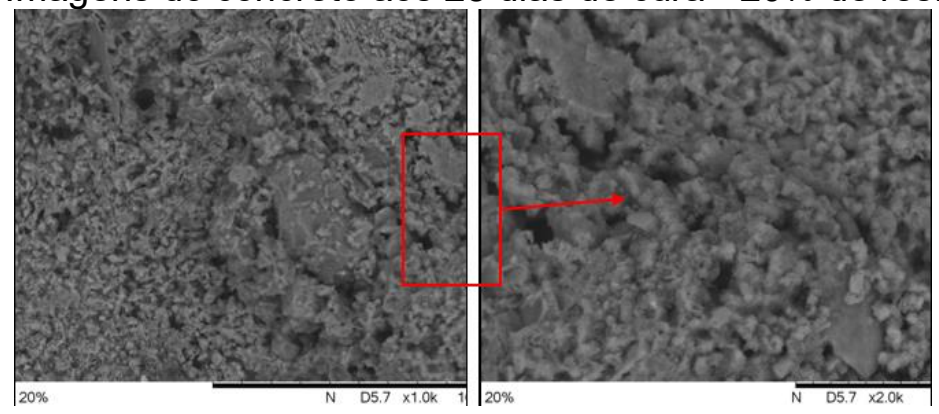

Fonte: Os autores.

\section{CONCLUSÕES}

Na preparação dos concretos com o rejeito pastoso de marmoraria, percebeu-se a necessidade de um volume maior de água do que foi previsto para o traço, a fim de garantir a confecção dos corpos de prova. Ainda assim, as composições, que receberam 10\% do RCMG, apresentaram maior desempenho, atingindo em média $35 \mathrm{MPa}$, atendendo às exigências normativas de resistência mecânica à compressão axial para pavers. As composições com esta proporção também apresentaram os menores índices de vazios e absorção de água. O concreto desenvolvido neste trabalho apresentou resultados laboratoriais satisfatórios, tornando-se viável a substituição parcial do cimento Portland para produção de pavers.

Esse trabalho contribuiu para redução da disposição do RCMG no meio ambiente, uma vez que esses resíduos podem acarretar impermeabilização do solo por apresentar partículas muito finas como comprovado na análise de granulometria e pode-se concluir que não ocorreu perda significativa de resistência mecânica com a substituição parcial do cimento Portland por resíduo de corte de mármore e granito nas proporções empregadas. 


\section{REREFÊNCIAS}

ALIABDO, A. A.; ELMOATY, A. E. M. A.; AUDA, E. M. Re-use of waste marble dust in the production of cement and concrete. Construction and Building Materials. v. 50, p. 28-41, 2014.

ALVES, M. S. Estudo das características e da viabilidade do uso de resíduos gerados no polimento de rochas graníticas como adição em concretos. 2008. 131 f. Dissertação (Mestrado em Construção Civil) - Universidade Federal de Minas Gerais, Belo Horizonte, 2008.

ANDRADE, T.; HELENE, P. Concreto de cimento Portland. In: Materiais de Construção Civil e Princípios de Ciência e Engenharia de Materiais. São Paulo: IBRACON, 2007.

ASSOCIAÇÃO BRASILEIRA DE NORMAS TÉCNICAS - ABNT. NBR 5738: Concreto Procedimento para moldagem e cura de corpos de prova. Rio de Janeiro: ABNT, 2016.

ASSOCIAÇÃO BRASILEIRA DE NORMAS TÉCNICAS - ABNT. NBR 7211: Agregado para concreto - Especificação. Rio de Janeiro: ABNT, 2009.

ASSOCIAÇÃO BRASILEIRA DE NORMAS TÉCNICAS - ABNT. NBR 9778:

Argamassa e concreto endurecidos - Determinação da absorção de água, índice de vazios e massa específica. Rio de Janeiro: ABNT, 2009.

ASSOCIAÇÃO BRASILEIRA DE NORMAS TÉCNICAS - ABNT. NBR 12.655:

Concreto de cimento Portland - Preparo, controle, recebimento e aceitação -

Procedimento. Rio de Janeiro: ABNT, 2015.

ASSOCIAÇÃO BRASILEIRA DE NORMAS TÉCNICAS - ABNT. NBR NM248:

Agregado - Determinação da composição granulométrica. Rio de Janeiro: ABNT, 2003.

ABREU, U.A.; RUIZ, M.S.; CARUSO, L.G. Perfil 7- Rochas dimensionadas e aparelhadas. In: RUIZ, M.S.; NEVES, M.R. (Coord.). Mercado produtor mineral do estado de São Paulo. São Paulo: I.P.T., 1990. p.137-151.

BRANDÃO, W.; SARDOU FILHO, R.; QUEIROZ, E.T. Mármore e granito e outras rochas ornamentais no Brasil. In: SCHOBBENHAUS, C.; QUEIROZ, E.T.; COELHO, C.E.S. (Coord.). Principais depósitos minerais do Brasil. Brasília:

D.N.P.M./C.P.R.M., 1991.

CEVIK, U.; DAMLA, N.; KOBYA, A.I.; CELIK, A.; KARA, A. Radiation dose estimation and mass attenuation coefficients of marble used in Turkey. Ann. Nucl. Energy, v. 37, n. 12, p.1705-1711, 2010.

CHIODI FILHO, C.; RODRIGUES, E. P. DE. Guia de Aplicação de Rochas em Revestimento: Projeto Brula. São Paulo: ABIROCHAS, 2009.

DNIT - DEPARTAMENTO NACIONAL DE INFRA-ESTRUTURA DE TRANSPORTE. Manual de Pavimentos Rígidos. 2 ed. Rio de Janeiro, 2004.

FIORITI, Cesar F. Pavimentos intertravados de concreto utilizando resíduos de pneus como material alternativo. 2007. Tese (Doutorado em Ciências da Engenharia Ambiental) - Universidade de São Paulo, São Carlos, 2007. 
GIACONI, W.J. Perfil atual da indústria de rochas ornamentais no município de Cachoeiro de Itapemirim (ES). Campinas, SP, 1998. 85 p. Dissertação (Mestrado na Área de Administração e Políticas de Recursos Minerais) - Universidade Estadual de Campinas, Campinas, 1998.

GONÇALVES, J.P. Utilização do resíduo de corte granito, como adição, em concretos. Dissertação de mestrado, NORIE, Universidade Federal do Rio Grande do Sul, Porto Alegre/RS, 2000. 135p.

HELENE, P. A Nova ABNT NBR 6118 e a Vida Útil das Estruturas de Concreto. In: Seminário de Patologia das Construções, 2, 2004, Porto Alegre. Proceedings. Porto Alegre: Novos Materiais e Tecnologias Emergentes, LEME, UFRGS, v. 1. p. 1-30, 2004.

IBRACON, Anais do $50^{\circ}$ Congresso Brasileiro do Concreto - CBC2008. Salvador, 2009.

KIHARA, Y; CENTURIONE, S. L. O Cimento Portland. In: Concreto: ensino, pesquisa e realizações. São Paulo: [s.n], 2005.

LLOPE, W.J. Activity concentrations and dose rates from decorative granite countertops. J. Environ. Radioact. v. 102, n. 6, p. 620-629, 2011.

LUCAS. D; BENATTI, C. T. Utilização de resíduos industriais para a produção de artefatos cimentícios e argilosos empregados na construção civil. Revista em

Agronegócios e Meio Ambiente, v. 1, n.3, p. 405-418. 2008.

MATTA, V. R.P.; APOLINÁRIO, E. C. A.; SANTOS; G. R. S.; RIBEIRO; D. V. Efeitos da adição do resíduo de corte de mármore e granito (RCMG) no desempenho de argamassas de cimento Portland no estado endurecido. IX Fórum Ambiental da Alta Paulista, v. 9, n. 1, p. 87-104, 2013.

MEHTA, P. K.; MONTEIRO, P. J. M., Concreto: Estrutura, Propriedades, Materiais, São Paulo, Pini, 1994.

MENEZES R. R.; NEVES G.A.; SOUZA J.; MELO W. A.; FERREIRA H. S.; Atividade pozolânica dos resíduos do beneficiamento do caulim para uso em argamassas para alvenaria. Revista Brasileira de Engenharia Agrícola e Ambiental. v.13, n.6, p.795801, 2009.

NEVILLE, A. Propriedades do concreto. 2. ed. São Paulo, Pini, 1982.

NEOBLOCO. Piso intertravado de concreto. Disponível em:

https://www.neoblocosp.com.br/produtos/piso-intertravado. Acesso em: 10 out. 2019.

PETRUCCI, ELADIO G. R., Materiais de construção., 9 ed., São Paulo, Globo, 2007.

RHINO PISOS. Instruções de colocação. Disponível em:

http://www.rhinopisos.com.br/mobile/instrucoes de colocacao. Acesso em: 10 out. 2019.

RODRIGUES, M. R. P; FERREIRA, O.P. Caracterização de compósitos produzidos com borracha de pneus inservíveis e resina poliuretana. Revista Iberoamericana de Polímeros. São Paulo. v. 11 n. 5. p. 274-283. 2010. 